\title{
A New Model of Psychological Education for General Aviation Trainees
}

\author{
Hongmei Wang \\ Civil Aviation Flight University of China \\ Guanghan, Sichuan Province, China \\ wanghongmeicn@163.com
}

\author{
Genhuai Xie, Jianjiang Zheng \\ Civil Aviation Flight University of China \\ Guanghan, Sichuan Province, China \\ Genhuai_x@163.com
}

\begin{abstract}
In order to promote the process of psychological education of general aviation trainees and strengthen the base of the psychological health, a new model of psychological education is put forward for related aviation students of general aviation universities. Firstly, it is essential for educators to teach in accordance with different aptitudes in apparent references. And it is instructive for the general aviation trainees, including pilots, air traffic controller, and maintenance, etc. Secondly, lots of principles are given in order to support for improving the psychological quality of students. Finally, the new class of model of psychological education is emphasized to discuss in the paper in the view of trainers and trainees.
\end{abstract}

Keywords-Psychological education; New Model; Psychological Health; Aviation trainees.

\section{INTRODUCTION}

It is a universal and particular for general aviation students in about the psychological health education. The universality denotes that they have the general psychological characteristics and psychological needs of general aviation college student. Due to this point we can draw on the successful experiences and models of general colleges to carry out the general of psychological health education. The particularity of general aviation university represents that the students need psychological health education in order to satisfy the needs of general aviation industry and it is necessary to adjust and plan the educational work whenever and wherever possible. It cannot be generalized, especially when the students want to have a good ability to be engaged in a job which is in the strong psychological situation. This requires the trainers to pay their attention when the general aviation trainees are in the training of psychological health education, which should be shouldered the importance duties of professional institutions, especially in general aviation universities.

\section{THE NECESSITY OF STRENGTHENING PSYCHOLOGICAL HEALTH EDUCATION WORK OF GENERAL AVIATION STUDENTS}

We all know that implementing the strategy of developing the country through science, technology and education and vigorously developing human resources. In the recent years, there are the huge demands for flight skilled talents with the rapid development of the general aviation in China. Now China is facing the restriction of human resources, especially about pilots, and also puts forward new requirements for associated pilots. Owing to the irreplaceability of flight talents, and the long training cycle and the guarantee the safety of aviation operation, pilots should be paid special attention to improve the psychological quality and intensify the ability construction. Many airline companies put forward many suggestions and requests from their own pilot team situation and their company development prospect, from the pilot recruitment, training mode of training colleges and universities. They all mentioned that it is important for psychological quality education in the process of pilot training. This should be strengthened the pilot's attention because the safety problem cannot be ignored from the beginning to the end and the psychological problems are most likely to lead to serious problems. Strengthening and improving psychological health education under the new situation implement is based on the frame of National Education Conference and the spirit of "National Long-term Education Reform and Development Plan (2010-2020)", and it will promote to the healthy growth of college students which is important way to train top creative talent. This is an important task to fully implement the party's education policy and construct human resources power. This is the important measures that the party deeply promoted to higher education reform, to strengthen and improve ideological and political education. Through the application of the principles of psychology and the methods of pedagogy, general aviation students will influenced thoroughly and it will help them to form a good psychological quality and regulating psychological condition, to develop potential, form a good personality and ideological character, and to promote the all-round development of students personality with the results of the mature and perfect life.

A. Strengthening Psychological Health Education Work for General Aviation Students. it is New Period to Fully Implement the Party's Education Policy, and is an Important Measure to Promote the Quality-Oriented Education in The Colleges of Civil Aviation

Civil aviation colleges and universities are main lands to culture aviation students, service airline in China. It is predicted that the demand of civil aviation pilots is about 3500 each year in the future. The training capacity of Civil Aviation Flight University (CAFUC), which is directly under the control of the Civil Aviation Administration of China (CAAC), is about 1500 people. And Civil Aviation 
University of China (CAUC) is about 100 people. So there is about nearly 400 gaps, as shown in Figure 1. Currently other domestic flight schools or training organizations that have been approved by the examination and approval of civil aviation regulations are about total 10 units, whose annual training capacity are approximately 500 people. The annual training capacity of 24 training organizations abroad is about 4000 people (actually training 1500 people per year for China).



Figure 1. Flight trainees proportional relationship

Generally speaking, large and medium-sized civil aviation colleges still are the important position for general aviation training students. In strategic, we have the plan to reconstruct pilot training ability, guaranteeing the quality of general aviation students, as well as requiring psychological health education workers of civil aviation colleges constantly to explore the psychological education training modes which are suitable for China's civil aviation development. Further raising awareness, domestic pilot's psychological ability is increased as soon as possible. We should seize the development opportunities and train more practical talents for general aviation.

B. Strengthening Psychological Health Education Work for General Aviation Students. it is Urgent Needs for Healthy Growth to Promotes Students' Comprehensive Development In the New Period

General aviation trainees are not only university students but also the special groups in universities. They are in a critical period of independence and mature because of the particularity of the employment demand. So they become particularly strong desire to grow up. But in the same time they tend to be self-orientation too high, coupled with age. It will lead to develop psychologically without full mature, stable, and so on. Some kinds of emergency problems will be appeared in the process of their study at school, such as psychological adjustment ability and suitability. Especially in the recent years, with the rapid development of civil aviation, the more demand for the pilot puts forward new more requirements. Therefore, it is important for the flight aviation colleges to strengthen students psychological health education work in the new period in order to further the allround development and healthy growth of the trainees, helping them to know and mastering their psychological law of development, promoting the development of self- consciousness and perfect, strengthening psychological immune ability.

C. Strengthening General Aviation Students Psychological Health Education Wor. it is an Important Part of Moral Education Work to Intensify and Improve Aviation Colleges and Universities in the New Period.

With the rapid growth of the civil aviation transportation, it has brought the significant historical opportunity for the development of the aviation colleges. At the same time, they also will be confronted with the fierce competition from both at home and abroad. In order to adjust to the needs of era development, the ideas must be further changed and the mind must be emancipated. The difficulties and problems encountered in advance must be solved with the advanced and the fine approach in order to adhere to the socialist direction of running a school, fully implementing the party's education policy, following the rules of the development of higher education. With the center of personnel training, teaching and training, and on the premise of flight safety, quality education must be actively carried forward. The high level specialized applied-type talents will be cultivated. Simultaneously they have the qualified political mind, the newly style, the strong foundation, the innovative spirit and the practice ability.

Through general aviation college psychological education work, a new model is explored continually. The generation of value judgment of trainee pilots is given, and the establishment and perfection of values are built. The establishment of moral cognition, moral emotion and moral consciousness of the firm of aviation trainees are developed to coordinate with each other. And in the process of mental health education and values education, Moral education work of aviation colleges and universities are enhanced, aimed at contemporary with the pertinence, effectiveness and initiative. And high-quality talents are cultivated and brought up to suit the development of Chinese civil aviation because it is an urgent need for moral education work in aviation colleges and universities to study and solve the new task. Therefore, it is inevitable requirement to strengthen the students' psychological health education to strengthen and improve moral education work of aviation colleges and universities.

\section{THE PRINCIPLES Followed TO STRENGTHEN PSychological HEALTh EdUCATION OF GENERAL AVIATION TRAINEES}

Psychological health education of general aviation trainees is based on the needs of the development of general aviation, education reform and psychological law of development for trainee pilots. And it is an important component of the quality-oriented education in aviation colleges and universities. So general aviation trainees' psychological health education work should be implemented as the following principles:

\section{A. Purpose Principles}

Psychological health education in aviation colleges aims to cultivate students' healthy psychology and sound 
personality. Because most of aviation trainees enrolled is already the adults, they have some certain experience in study and social life. In view of psychological health education for the aviation trainees should be specially emphasized on the terms of practicability and maneuverability. And the psychological health education work should be focused on the knowledge imparted which is related to the aviation industry. The knowledge involves the psychology information and psychological health information. The advantages are to help them to enhance psychological adaptation and endurance ability and they have self-adjusting and self-control functions in the end.

\section{B. Sustainable Development Principles}

Psychological health education for aviation trainees is an ongoing work and should be adhered to work hard in order to the efficacious results. For a trainee pilot when enrolled initially, everyone is required to be paid attention and given the follow-up treatment if he has the psychological problems, it is not good idea that the behavior based on the simply formalized "dialogue" will be largely beneficial to solve the psychological problems of aviation trainees. Paying close attention for psychological health education of aviation trainees, solving student pilot psychological problems, eliminating psychological barriers, we should improve psychological qualities of the whole flight trainees which are regards as a starting point. And we focus on helping all flight students to understand mental health basics, optimizing individual psychological quality, enhancing mental adaptability and the ability to adapt to social life. Therefore, in the educational process, teachers of aviation academies should understand and grasp the common need of students to create conditions so that as many students participate in the activities of psychological health education in order to effectively perform psychological health education functions, i.e. "prevention" and "promote". And all students are promoted all-round development.

\section{Teaching Students in Accordance with Their Aptitude Principle}

Flight trainees from all over the world, different family conditions, and individual differences, at the same time have their own personality traits. Psychological health education of aviation colleges should be on the basis of the ideology that giving judicious guidance according to circumstances, and teaching students in accordance of their aptitude. Psychological health education educators can adopt different methods, techniques and means to start several forms of related activities improving each flight students' psychological health level, and ultimately achieving the objective of the students' psychological health development.

\section{Protecting Privacy Principle}

According to the sacred constitution, everyone's privacy is protected by the law. In the process of carrying out psychological health education work in aviation colleges and universities, the principle of confidentiality is of first importance to follow, and it is the basic quality for each psychological education worker to protect the information of personnel case and don not open individual records. Only in this way, the psychological consultants do have peace of mind, and be at home and open when he faces with the professional consultant. The educators are targeted to carry out psychological health education work.

\section{Constructing A New Mode Of General Aviation STUdENTS PSYCHOLOGICAL HEALTH EDUCATION WORK}

As a professional flight training colleges, psychological health status of students has become an important factor which affects the quality of personnel training. Therefore, we should strengthen the flight student psychological health education, and strive to build a new mode of psychological health education of flight trainees in order to improve the psychological quality of aviation students. First of all, pilot training qualification standards must be tight, strictly selecting flight trainees, and controlling entrance standard of flight students. Secondly, training standard must be improve strictly, and we must correctly handle the relationship between safety and quality, and draw up strict selection criteria, and unswervingly put good technical clearance. Theoretical training standards are necessary to tighten up, and we want to work hard for improving the students' knowledge level of psychological quality.

Good psychological quality is the basis of the quality of personnel. And it is necessary subjective condition for the scientific and cultural knowledge. Psychological education will be truly effective only to follow the rule of the psychological occurrence, development and activities. Therefore, it is the key for flight trainee's quality education to improve the psychological quality.

\section{A. Construction of Interchange-Type Mental Health Education Model}

The pilot psychological health education is a systematic project, following the policy of quality, scale, structure, benefit harmonious development. The relationship between the characteristics and general, quality and scale, qualifications and skills are correctly handled. Viewing from the overall situation, knowledge is the foundation, and ability is fundamental. One should pay attention to imparting professional knowledge, also should impart great importance on the training of students' learning ability, practice ability and innovation ability, which is to promote quality education. The psychological health education work which is as part of the college moral education, the more investment on psychological health education should be invested, including the hardware and software. The psychological education workers professional should be good at using the education method of psychology education guidance to teach flight trainees. We can ensure the psychological health education is scientific and orderly only by the connection up and down are dredged, horizontal linkages and collaborative work, the interchange network psychological health education work and part-time and full-time staff. 


\section{B. Creating a New Special Education and Universal Education}

With the aggravating teaching task, and the increased number of students, a new situation is appeared for the current flight trainees' work. Regularly organization of management staff of flight trainees is made to analyze the condition comprehensively based on the practical situations. We should adhere to focus on the characteristics of groups and individual psychology, to develop phased education programs.

For example, propaganda media, propaganda and popularize mental health knowledge such as websites, radios, newspapers, periodicals, show windows, are specialized in psychological health education and widen the channel of the psychological education.

\section{Carrying out Educational and Pertinence of the Campus Cultural Activities}

Began school education standardization process from flying cadet school, this step will make students learn faster flight school, to meet the requirements of the school environment and the management, a good foundation for learning in school life. As for the special education school conditions, school management education, style and discipline education, aimed at professional education planning, theme class meeting and be familiar with the campus environment. The implementation of this process, will be to save the education resources, standardized education process play a role in promoting. Beautiful environment, good school spirit, and colorful cultural life, quiet the mind, edify sentiment, open mind, also can be joyful disposition, inspire ambition. Therefore, to strengthen the psychological health education of flying cadets, attention should be paid to the construction of campus culture, vigorously develop diverse forms, be lively and vivid campus cultural activities, the development of online PPS communication platform, let students share flight experience. These measures are taken, in short to guide the formation of good campus atmosphere can play an important role in the work of students, flight, psychological education has a long way to go, need to innovate in practice, through the positive efforts, will be able to promote the psychological education of flying cadets to a new level.

\section{ACKNOWLEDGMENT}

This research is supported by CAFUC Normal Foundation Project (J2011-67 and Q2011-99)

\section{REFERENCES}

[1] Xie Bin contemporary university urgent task: Mental Health Education. Machinery Industry Higher Education Research, 2001, (3).

[2] Dong Liren. Role of Psychological Health Education in the ideological and political education in the complementary effects of Chinese Higher Education, 2001, (10).

[3] Cui Wei. Universal psychological education, shaping the Students' Healthy Personality. Chinese Higher Education, 2001, (20).

[4] Xu Jianjun. Mental health education three meetings. Modern University Education, 2002, (6).

[5] Lu Xiaoying. Use of psychological knowledge to improve ideological education results. Ideological Education Research, 2002, (11). 